\title{
USING TRIPLE-LOOP LEARNING TO IDENTIFY ADAPTIVE BEHAVIOUR OF RESILIENT SUPPLY CHAIN
}

\begin{abstract}
The contemporary environment of supply chains is characterized by discontinuity, being the source of unpredictable changes producing effects that are difficult to determine. Underestimating and not including the discontinuity in the managerial concept makes the supply chain homomorphic with respect to reality, thus, it is reflected only approximately (Jędralska, 1992). In other words, the situation of discontinuity is caused by the unreliability of the current management model. The answer to the discontinuity may be the formation of resilient supply chains that are aimed at developing specific patterns of adaptive behaviour. The aim of the article is to recognize the adaptive behaviours of a resilient supply chain in light of the assumptions of triple-loop learning in an organization. In the first part of the paper, the issue of a resilient supply chain is discussed, highlighting its adaptive capability. Next, the mechanism of preadaptation - adaptation of the supply chain based on triple-loop learning is explained. The final part of the paper presents the basic components of a resilient supply chain determining the adaptive behaviour consistent with triple-loop learning.
\end{abstract}

Keywords: learning, supply chain, preadaptation, resilience

\section{Introduction}

The concept of a resilient supply chain had covered a long path of development before it was possible to consider its essence in a theoretical approach and implement the assumptions in the practice of business. Many different definitions of the category of a resilient supply chain can be found in the literature, most of which 
emphasizes the dynamic nature of the organization's functioning ${ }^{1}$. A key issue indeed is maintenance and development of the adaptive capabilities of a resilient supply chain that enable functioning when faced by a discontinuity (Juttner, Maklan, 2011). In the opinion of Sutcliffe and Vogus (2003), the resilient supply chain has the capability of 'rebounding' when disturbances or other problems have occurred. According to Wildavski (1988), a resilient supply chain has a dynamic capability of organizational adaptation that enables growth and development over time. In the opinion of Christopher and Peck (2004) resilience in the context of a supply chain defines the ability to return to the original state or to move into another that is more desirable after the occurrence of a specific disruption. This is in line with the etymological understanding of the resilience category, which dates back to the Latin language and means 'bounce', 'rebound' (Ponis, 2012). Hence, it means the ability to absorb disturbances and maintain the basic functions and structures of the system (Walker, Salt, 2006). Therefore, resilience can mean the system's ability to return to the state from before the disturbance (Petchey, Gaston, 2009). Pettit et al. (2010) emphasize nonetheless that from the point of view of a resilient supply chain, it is not the return to the original state that is important, but the ability to learn and to move the system to a new state. In light of the foregoing, Peterson et al. (1998) note that resilience combines two opposing aspects - one focused on maintaining the efficiency of the function performed, the other relating to the existence of a specific function. The former approach is consistent with the engineering resilience and means ensuring the equilibrium and flexibility. The latter perspective, on the other hand, refers to ecological resilience and emphasizes the importance of a state far from equilibrium, which provides the system with the ability to absorb disturbances and maintains its basic functionality (Holling, 1996). The concept of resilience in relation to the social system refers to adaptation, organizational learning and self-organization that enable the overall ability of the system to face disruptions (Folke, 2006). A resilient supply chain is of a dynamic nature, namely, it has great capabilities of adaptability to the environment (Ponomarov, Holcom, 2009). Specific links in the supply chain change under the influence of relations with other participants of the system (Brodbeck, 2002).

\section{Preadaptation - adaptation of a supply chain based on triple-loop learning}

The adaptive behaviour consistent with the triple-loop learning principles can be called preadaptation (Ameli, Kayes, 2011). Preadaptation is considered as the most advanced learning process that can be referred to as process learning (Buechel, Probst, n.d.). It reaches out to the deepest layers of the organization's diversity potential (Flood, Romm, 1996) that can be the source of its creativity. In other words, preadaptation can occur when managers are able to identify and use the organization's diversity potential (Hamel, Breen, 2008). Supply chains include diverse

1 An extensive review of the literature on the concept of the resilient supply chain is presented in: Ponomarov and Holcom (2009); Hohenstein et al. (2015); Mandal (2014); Pereira, Christopher and Lago Da Silva (2014). 
entities, specialists focused on their key competences (suppliers, manufacturers, distributors, logistics operators, providers of nonlogistic services) and functionally diverse areas of interrelation (logistics, marketing, production, research and development, finance, administration, etc.), which are the source of organizational creativity and enable the chain preadaptation. Hence, the mentioned differentiation means simplification and selection, namely, perceiving and responding only to specific aspects of the environment that may have a potential impact on the organization's survival and development. Focusing the effort on a selective activity, the organization preserves freedom and autonomy, but at the same time creates uncertainty resulting from omission of important elements in the process of selection and the lack of response to these elements (Steinmann, Schreyogg, 2001). In other words, the triple-loop learning is manifested in the form of collective awareness (Stacey, 2011). This means that the assimilated or acquired learning enables the creation of new structures and strategies. In the opinion of Batesson (Rokita, 2015) triple-loop learning means learning to learn. Previous learning is reflected in triple-loop learning, hence, the organization learns to improve its learning. In this way values as well as strategies and expectations can be modified (Argyris, Schön, 2006). In the process of learning, the supply chain is able to transform as its internal relationships are visible and obvious. Patterns of the organization's links with the environment are also recognizable. A deeper understanding of these patterns and possible consequences of the actions taken leads to changes in the structure. Learning according to the third loop is of a direct nature that allows identifying the role and importance of the organization (Morgan, 1996). From the point of view of the triple loop, the development of the organization's capability of learning is a prerequisite for survival and development in the face of the increasing complexity and dynamics of the environment (Georges, Romme, Witteloostuijn, 1999). Figure 1 shows the ideogram of preadaptation, the adaptive behaviour of a supply chain according to the assumptions of triple-loop learning.

Preadaptation includes corrective actions with a different degree of advancement from the point of view of the organization's mental model. On the one hand, they can be relatively shallow and involve a simple or relatively advanced modification of the existing activities and reach goals/values, and even structures and processes. Modification of the existing activities does not require using unique mental models to solve a specific decision problem. Its essence is the routine, cyclical nature of changes to which the supply chain can successfully respond in a manner analogous to the past. Therefore, recognizing a deviation and its simple correction enables the organization to continue the current policy or achieve previously planned goals. A more advanced pattern of corrective actions concerns the needs, motives, interests and values rooted in the organization. In this case, the necessary changes in the organization may require revision of the existing goals and tasks (Rokita, 2015). This is most of all the case when specific consequences of the action taken lead to questioning the current mental model of the organization, i.e. the standards and assumptions underlying the model. This means that complex learning forces not only a correction of activities, but above all a modification of the model on the basis of which these activities are conducted. 


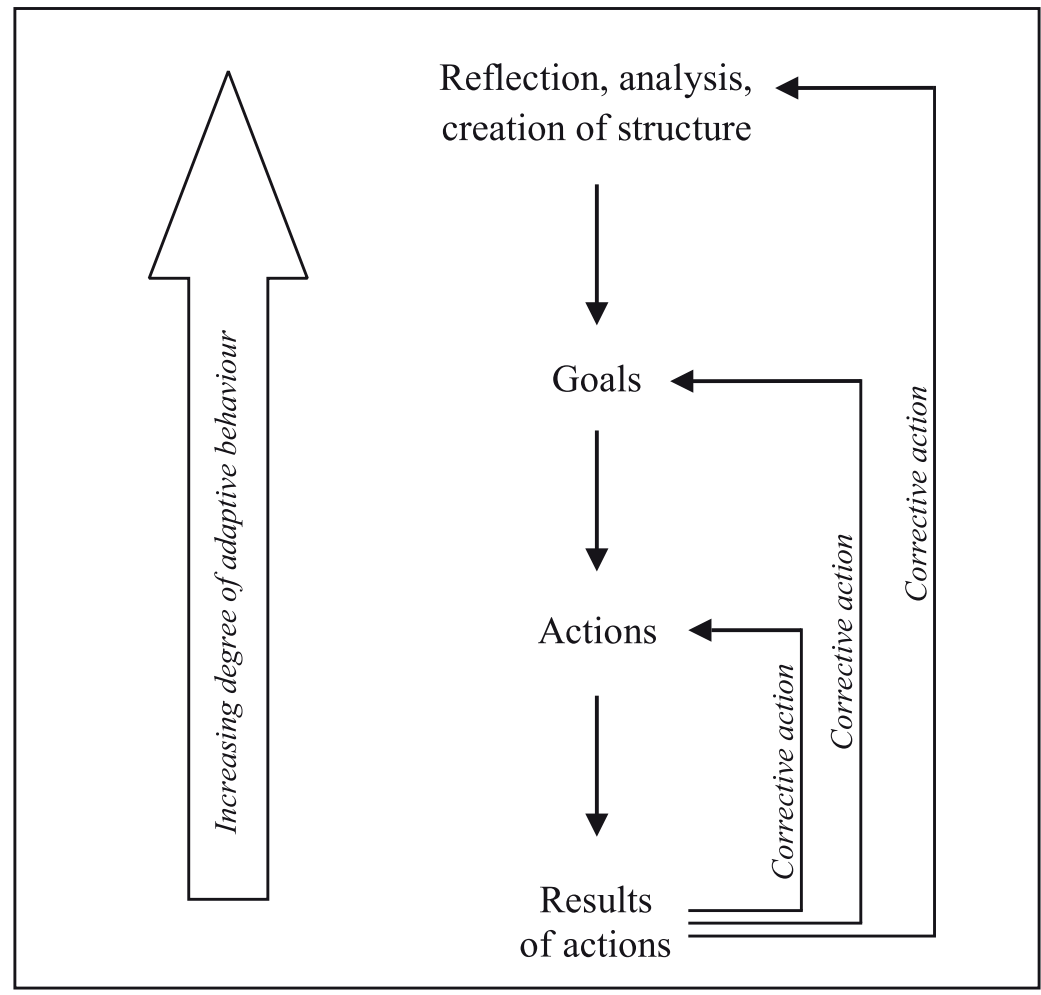

Figure 1. Adaptation of the supply chain according to triple-loop learning Source: (own elaboration based on: Rokita, 2005)

The most advanced adaptation, constituting the quintessence of preadaptation goes much deeper into the mental model of the organization ${ }^{2}$. It modifies structures and processes, leading to a complete change of the existing pattern of behaviour. However, to achieve the expected state, at first the system should fall into chaos, to be reborn to a new state, more adequate to the environment. The ability of the supply chain to move from one state to the next one requires identification of change impulses, their analysis, selection and reactive response. Preadaptation emphasizes the necessity of the system to move from the state of equilibrium to the state of disequilibrium - Figure 2.

According to Figure 2, the system remains in the state of equilibrium 1 until moment $t_{1}$, then it moves to the state of disequilibrium. In this way, the system is heading in the direction of disequilibrium, attracted by infinity to an unstable or completely random pattern of behaviour. Heading towards disequilibrium is realized by a reinforcing (amplifying) - feedback. This type exponentially amplifies initially small disturbances without any internal limitations of the system, pushing the system towards the edge-of-chaos. It offers a diversity whereby the system is moving towards a creative, innovative and sometimes surprising state (Stacey,

2 According to the idea of encapsulation, less advanced adaptive behaviours of the supply chain are included in more advanced patterns. More on this topic in: Świerczek (2017, pp. 46-71). 
1996). As a result, the system is able to achieve a new, completely different state (at moment $t_{2}$ ) which will allow a much better adaptation of the supply chain to the ambient conditions. Using the opinion of Thietart and Forgues (1995), it can be said that it is chaos (the edge-of-chaos) that is a distinctive state for the supply chain preadaptation.

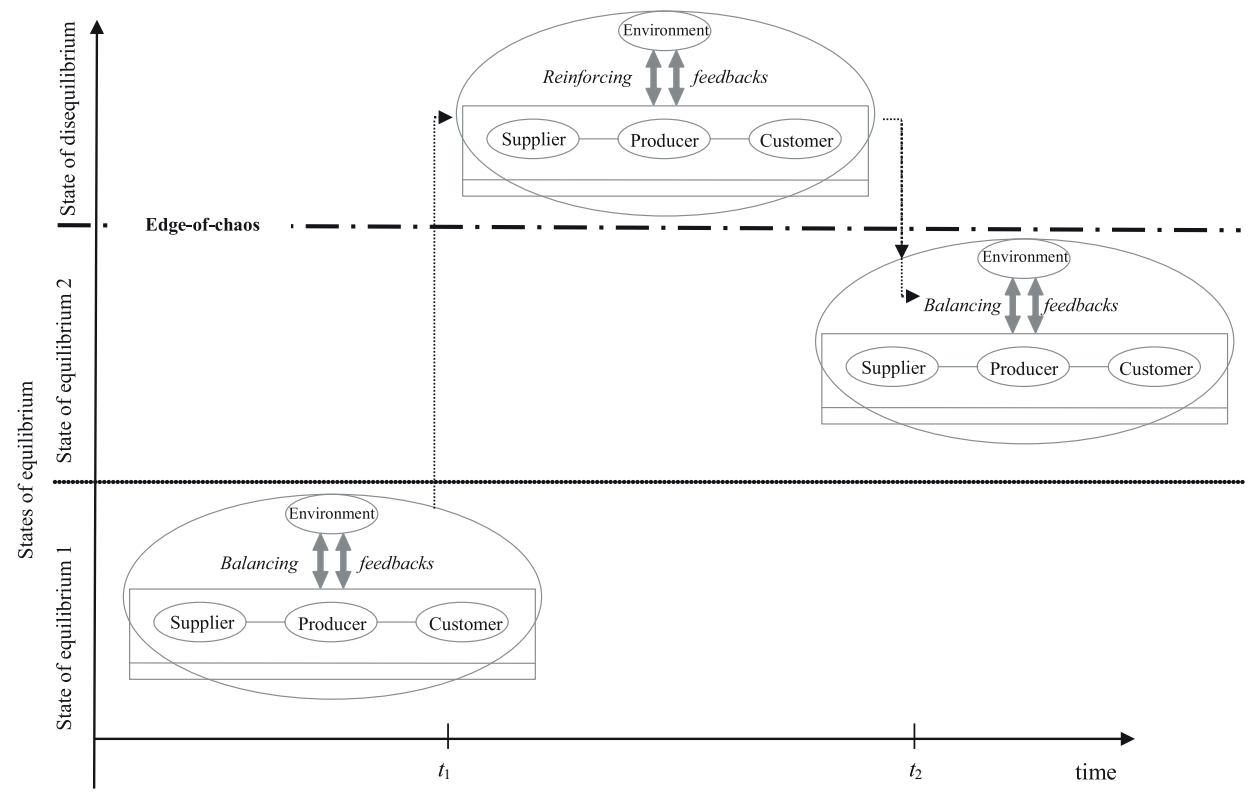

Figure 2. Adaptive behaviour of the supply chain according to triple-loop learning - conceptual scheme

Source: (own elaboration)

\section{Resilient supply chain components determining adaptive behaviour consistent with triple-loop learning}

The functioning mechanism of a resilient supply chain based on the third loop of learning enables the continuity of operation in an uncertain environment, and thus the ability to adapt and perform specific functions in an environment full of challenges and tensions (Ponomarov, Holcom, 2009). The main components determining the mechanism of functioning of a resilient supply chain include agents forming a specific supply chain, the edge-of-chaos and the ability to identify dissipative structures as a result of emergence. The conceptualization of a resilient supply chain by the basic components determining preadaptation is shown in Figure 3. The interrelationships between the resilient supply chain and its functioning environment are manifested by the occurrence of feedback loops (both balancing and reinforcing) and the reciprocity of influence referred to as coevolution. 
A resilient supply chain comprises many enterprises that can be described as agents. Agents influence the course of events in the supply chain as they decide on the inclusion of a specific link in the implementation of specific tasks, strive for expansion into new markets, implement integrated processes of product development with suppliers and customers (Choi, Dooley, 2001). Following interorganizational negotiations and creation of integrated decision centres in the supply chain, enterprises share common patterns that allow reducing transaction costs and increasing the communication efficiency. Agents in the supply chain have their own specific objective, which may be striving to secure a privileged position in the supply chain, increase the bargaining power of certain enterprises, identify reliable sources of material supply, develop a niche market, a stable market, etc. In addition to particular objectives in the resilient supply chain, a common goal is also formulated, achieved by matching the operating parameters to other participants in the supply chain. Owing to this, the supply chain operation can be regulated using the so-called 'invisible hand' that generates order and spontaneity at a given time. Therefore, enterprises should constantly observe structures selected within the supply chain and adjust their specific goals to the group of companies constituting a specific supply chain.

The key to the efficient functioning of agents in the resilient supply chain is adjustment and flexibility as well as the will to make deeper corrections and redefine the existing patterns of functioning facing the changes revealed in the environment (Choi, Dooley, 2001). Therefore, agents interact with each other in dynamic interactions, and their behavioural patterns take into account changes occurring in the environment, hence, mutual interactions allow generating behavioural patterns at the level of the whole supply chain (Stacey, 1994). Lewin and Regine (Stacey, 1994) include agents in one of the two groups: supporting and participating agents who contribute to the development of the system, and selfish and calculating agents who show reluctance to participate in the smooth functioning of the system. It should be noted that agents are specific entities of the resilient supply chain that are different from other links. They are characterized by autonomy (their actions are initiated within the system, without any external influence), flexibility (enabling proactive behaviour) and their own control mechanisms (Nilsson, Darley, 2006). In addition, agents in a resilient supply chain are heterogeneous, they have their own goals which they strive to attain under specific constraints and with different patterns of behaviour. The heterogeneous nature of agents contributes to the establishment of relations between them, if the agents had the same knowledge and characteristics (and thus they were homogenous), then they would not have the motivation to cooperate (Wycisk, McKelvey, Hulsmann, 2008). The behaviour of a particular agent changes dynamically as it remains in close interdependence with other agents. The behaviour of agents is determined by specific internal policies, and the behaviour of other agents which affects the non-linear nature of these interdependencies (Nilsson, Darley, 2006).

The result of collective behaviour of agents is a specific pattern of behaviour that agents would not achieve by acting individually. This is the reason why the behaviour of the resilient supply chain remains unpredictable and different than expected. As a result, the system can take advantage of emerging new opportunities 
(Bonabeau, 2002). Although the final shape of the supply chain may be unknown, individual enterprises participate in its creation by means of decisions taken locally. In the case of a resilient supply chain, the leading link generally selects enterprises with which it initiates and implements multi-entity activities. While this affects direct partners (suppliers and/or customers) and sometimes second-order indirect partners, it is generally not possible to select companies located further down the flow of products in the supply chain (e.g. third- and fourth-order links). As a result, these links remain outside the regulatory influence of the company leading in the supply chain, ensuring autonomy, which in turn enables self-organization of the system.

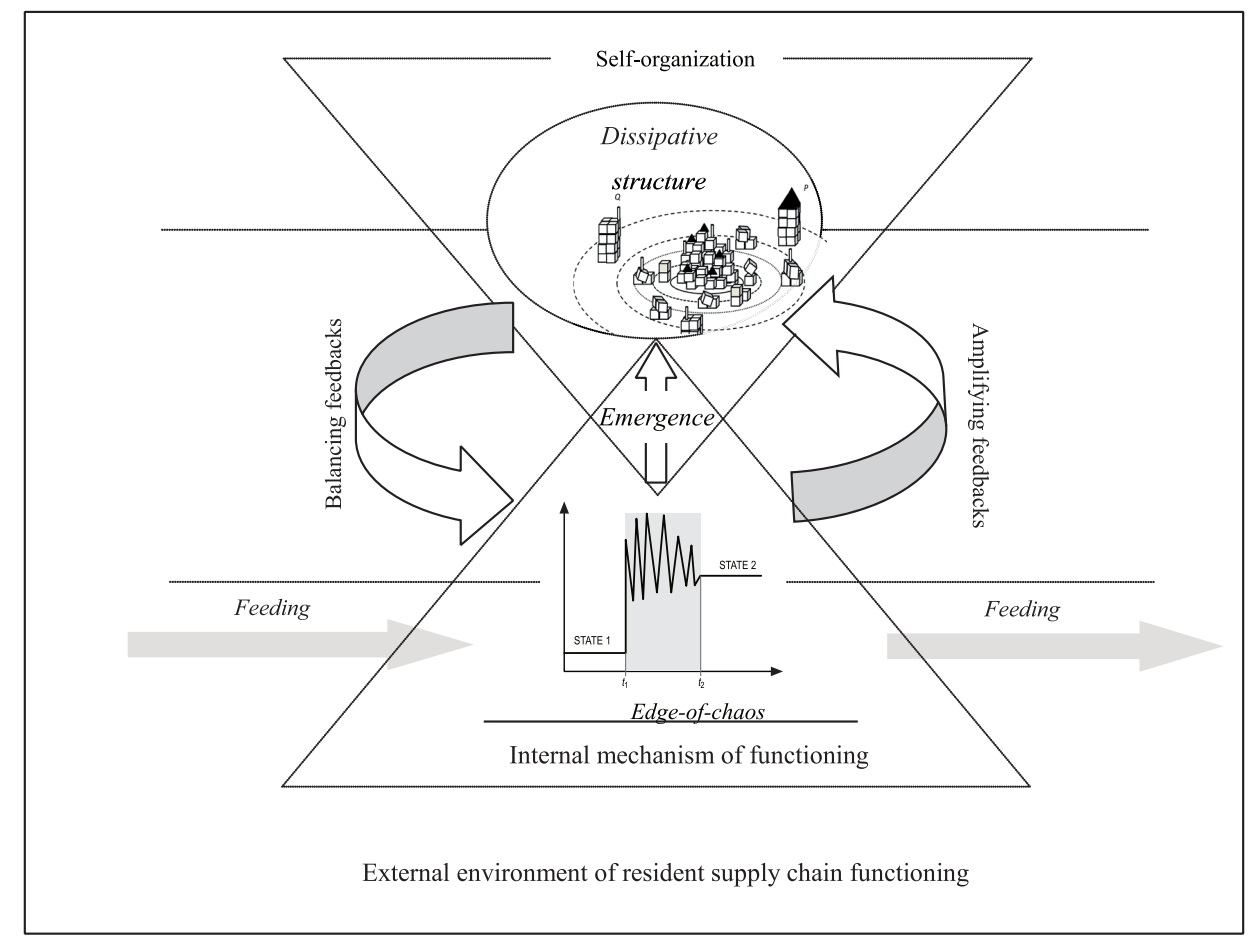

Figure 3. Basic components of resilient supply chain Source: (own elaboration)

Self-organization occurs when the system remains in a state far from equilibrium, in other words, in which it reaches a critical point. This point enables generating a new different quality structure or behaviour pattern that cannot be predicted based on the previous state of the system. The newly created structure is referred to as a dissipative structure, since it derives material and information supplies to maintain the new state in which the system is located (Stacey, 1994). Imported resources from the environment are dispersed in the system, so that they push it towards disintegration. Nevertheless, the structure of the resilient supply chain has the ability to renew, as it is fed by resources from the environment (Stacey, 1994). In practice, there should be a minimum degree of coherence (links) between 
actors in the supply chain, otherwise the system would be doomed to failure (Choi, Dooley, Rungtusanatham, 2001). The new pattern of the system's behaviour, created as a result of self-organization cannot be explained through the prism of the characteristics of the links forming a specific system and the relationship between these links. This means that the newly created structure is emergent (Stacey, 1994), probabilistic, and not deterministic. In other words, the resilient supply chain structure depends on local decisions of its links and on the way in which the choices made are combined to identify an organization of a probabilistic nature (Choi, Dooley, Rungtusanatham, 2001). Therefore, emergency means a process by which patterns or global structures emerge under the impact of local interactions (Bergmann, Lichtenstein, 2000). This refers to the tension between the striving for control and the emergence in the resilient supply chain. Insofar a specific link (e.g. manufacturer) can control the actions of direct partners (suppliers and customers), then it can extend its control over them. Nonetheless, directly related enterprises also have their partners, with whom they can shape inter-organizational relations on a voluntary basis. In this way, emergence appears, which means the decreasing impact of the leading link in the supply chain on other enterprises, in particular those that are not directly related to it (Choi, Wu, 2009). Paraphrasing Letiche's observations (2000), it can be concluded that emergent properties appear when the system surpasses the components of which it is built as a result of self-organization. Notwithstanding the fact that an accurate prediction of future behaviour of the system is difficult, nonetheless certain archetypes of such behaviour can be often found. The unpredictability of future behaviour patterns of the system corresponds to its incredible sensitivity. The smallest level of uncertainty can escalate. For example, a distortion caused by a small change in the functioning of the consumer market can be amplified and oscillate in the form of 'wild' totally uncontrolled fluctuations transferred onto other actors in the supply chain.

A major change in the existing functional pattern of the resilient supply chain may occur when the system influences its organizational boundaries by including or excluding specific agents from the supply chain structure, as well as by establishing or eliminating specific inter-organizational relations (Choi, Dooley, Rungtusanatham, 2001). Nevertheless, self-organization in the resilient supply chain does not appear in a linear and sequential manner. It occurs rather parallel, hence, it cannot be described by way of linear cause and effect relationships, which give similar effects in the short and long term. On the contrary, according to the systematics of analytical models proposed by Rokita (2011), a resilient supply chain can be presented by means of a non-linear model in which the cause and effect are separated from each other in time and space (Senge, 1990). A similar opinion is formulated by Wieck et al. (2008) who believe that resilience enables creation of a theoretical basis explaining the irregular behaviour of an organization in the conditions of increasing complexity and dynamics. Hence, the resilient supply chain includes network-related links, whereby causal relationships manifest a non-linear nature (Choi, Dooley, Rungtusanatham, 2001). Non-linear dependencies can be observed not only inside the supply chain, but also when analyzing the interaction between the supply chain and its surroundings. They manifest themselves in the form of balancing (stabilizing) and reinforcing feedback loops. Hence, the behaviour pattern 
of the resilient supply chain is subject to change as a result of the reciprocal impact of feedbacks, pushing the system to the edge of chaos or towards the equilibrium.

\section{Conclusions}

The presented considerations are aimed at recognizing the adaptive behaviours of a resilient supply chain in light of the assumptions of triple-loop learning in an organization. The triple learning loop explains the preadaptive capability of a resilient supply chain owing to which the organization acquires the ability to cope with the discontinuity of the environment. The basic components of a resilient supply chain determining the adaptive behaviour based on triple-loop learning that should be mentioned include: agents forming a specific supply chain, the edge-of-chaos and the ability to identify dissipative structures. They create the dynamics of changes in the supply chain being a basic determinant of resilience. The economic practice provides examples of resilient supply chains which have been able to survive and develop due to specific components determining the adaptive behaviour based on triple-loop learning. The supply chain of Toyota which restored its operational capacity within a period of a few days after a fire at one of their major suppliers (Aisin Seiki), thus avoiding several months of paralysis of operation of more than a hundred of dependent links may serve as an example (Nishiguchi, Baaudet, 1998). In the case of Toyota's supply chain, enterprises operating similarly to agents had the capability of balancing on the edge of chaos and unveiling dissipative structures, which made the supply chain capable of surviving and developing in the face of a discontinuity in the environment.

\section{Acknowledgment}

The study was financed by the National Science Centre as a research project No. DEC-2012/05/E/HS4/01598.

\section{References}

Ameli, P., Kayes, D.C. (2011), Triple-loop learning in a cross-sector partnership, The Learning Organization, 18(3), pp. 175-188.

Argyris, C., Schön, D.A. (2006), Die Lernende Organisation. Grundlagen, Methode, Praxis, Klett-Cotta, Stuttgart.

Bergmann-Lichtenstein, B.M. (2000), Emergence as a process of self organizing. New Assumption and insights from the study of non-linear dynamic systems, Journal of Organizational Change Management, 13(6), pp. 526-544.

Bonabeau, E. (2002), Predicting the unpredictable, Harvard Business Review, 80(3), pp. 109-16. Brodbeck, P.W. (2002), Complexity theory and organization procedure design, Business Process Management Journal, 8(4), pp. 377-402.

Buechel, B., Probst, G. (n.d.), From Organizational Learning to Knowledge Management, p. 6. Available from https://archive-ouverte.unige.ch/unige:5858 [Accessed 30 January 2018].

Choi, T., Wu, Z. (2009), Go ahead, leap: Triads and their practical and theoretical import. In response to 'To leap or not to leap: Triads as arbitrary subsets of networks of connected dyads' by Anna Dubois, Journal of Purchasing and Supply Management, 15, pp. 269-270. 
Choi, T.Y., Dooley, K.J., Rungtusanatham, M. (2001), Supply networks and adaptive systems: control versus emergence, Journal of Operations Management, 19, pp. 351-366.

Christopher, M., Peck, H. (2004), Building the Resilient Supply Chain, International Journal of Logistics Management, 15(2), pp. 1-13.

Coutu, D.L. (2002), How Resilience Works, Harvard Business Review, May, pp. 46-51.

Flood, R.L., Romm, N.R.A. (1996), Diversity Management: Triple Loop Learning, Wiley, Chicester.

Folke, C. (2006), Resilience: The emergence of a perspective for social-ecological systems analyses, Global Environmental Change, 16, pp. 253-267.

Georges, A., Romme, V., van Witteloostuijn, A. (1999), Circular organizing and triple loop learning, Journal of Organizational Change Management, 12(5), pp. 439-453.

Hamel, G., Breen, B. (2008), Zarządzanie jutra [Management of tomorrow], Harvard Business School Press, Red Horse, Warsaw, pp. 199-200.

Hohenstein, N.-O., Feisel, E., Hartmann, E., Giunipero, L. (2015), Research on the phenomenon of supply chain resilience, International Journal of Physical Distribution and Logistics Management, 45(1/2), pp. 90-117.

Holling, C.S. (1996), Engineering Resilience versus Ecological Resilience, In: Schulze, P. (Ed.), Engineering within Ecological Constraints, National Academy, Washington DC, pp. 31-44.

Jędralska, K. (1992), Zachowania przedsiębiorstw w sytuacjach niepewnych i ryzykownych [Behaviour of enterprises in uncertain and risky situations], University of Economics, Katowice, p. 12.

Juttner, U., Maklan, S. (2011), Supply chain resilience in the global financial crisis: An empirical study, International Journal of Supply Chain Management, 16(4), pp. 246-259.

Letiche, H. (2000), Phenomenal complexity theory as informed by Bergson, Journal of Organizational Change, 13(6), pp. 545-557.

Mandal, S. (2014), Supply chain resilience: a state-of-the-art review and research directions, International Journal of Disaster Resilience in the Built Environment, 5(4), pp. 427-453.

Morgan, G. (1996), Images of Organization, SAGE Publications, London.

Nilsson, F., Darley, V. (2006), On complex adaptive systems and agent-based modelling for improving decision-making in manufacturing and logistics settings experiences from a packaging company, International Journal of Operations and Production Management, 26(12), pp. 1351-1373.

Nishiguchi, T., Baaudet, A. (1998), The Toyota Group and the Aisin Fire, Sloan Management Review, pp. 49-59.

Pereira, C.R., Christopher, M., Lago Da Silva, A. (2014), Achieving supply chain resilience: The role of procurement, International Journal of Supply Chain Management, 19(5/6), pp. 626-642.

Petchey, O.L., Gaston, K.J. (2009), Effects on ecosystem resilience of biodiversity extinctions and in the structure of regional species pools, Theoretical Ecology, 2(3), pp. 177-187.

Peterson, G., Allen, G.R., Holling, C.S. (1998), Ecological Resilience, Biodiversity and Scale, Ecosystems, 1(1), pp. 6-18.

Pettit, T.J., Fiksel, J., Croxton, K.L. (2010), Ensuring supply chain resilience: Development of a conceptual framework, Journal of Business Logistics, 31(1), pp. 1-22.

Ponis, S.T. (2012), Supply Chain Resilience: Definition, of Concept and its Formative Elements, Journal of Applied Research, 28(5), pp. 921-930.

Ponomarov, S.Y., Holcom, M.C. (2009), Understanding the concept of supply chain resilience, International Journal of Logistics Management, 20(1), pp. 124-143.

Rokita, J. (2011), Myślenie systemowe w zarządzaniu organizacjami [System thinking in organization management], University of Economics, Katowice.

Rokita, J. (2005), Zarzadzanie strategiczne [Strategic management], PWE, Warsaw.

Senge, P. (1990), The Fifth Discipline: The Art and Practice of the Learning Organization, Doubleday/Currency, New York. 
Stacey, R. (1994), Strategic Management and Organizational Dynamics, Pitman Publishing, London, pp. 240, 242, 276, 278.

Stacey, R.D. (1996), Complexity and Creativity in Organizations, Berrett-Koehler Publishers, San Francisco, p. 57.

Stacey, R. (2011), Strategic Management and Organisational Dynamics. The challenge of complexity to ways of thinking about organizations, Prentice Hall, London.

Steinmann, H., Schreyogg, G. (2001), Zarzadzanie. Podstawy kierowania przedsiębiorstwem. Koncepcje, funkcje, przykłady [Management. The basics of business management. Concepts, functions, examples], Wrocław University of Technology, Wrocław.

Sutcliffe, K.M., Vogus, T.J. (2003), Organizing for Resilience, In: Cameron, K., Dutton, J.E., Quinn R.E. (Eds.), Positive Organizational Scholarship, Berrett-Koehler, San Francisco.

Świerczek, A. (2017), Typologia zachowań adaptacyjnych łańcucha dostaw [Typology of adaptive behaviour of supply chain], In: Kisperska-Moroń, D., Niestrój, K., Świtała, M. (Eds.), Budowanie łańcuchów dostaw jutra w świetle teorii i wyników badań [Building tomorrow's supply chains in light of theory and research results], University of Economics, Katowice, pp. 46-71.

Thietart, R., Forgues, B. (1995), Chaos theory and organisation, Organisation Science, 6(1), pp. 19-31.

Walker, B., Salt, D. (2006), Resilience thinking: sustaining ecosystems and people in a changing world, Island Press, Washington.

Weick, K.E., Sutcliffe, K.M., Obstfeld, D. (2008), Organizing for high reliability: processes of collective mindfulness, In: Boin, A. (Ed.), Crisis Management, Sage Library, Thousand Oaks, California, pp. 31-66.

Widlavsky, A. (1988), Searching for Safety, Transaction Books, New Brunswick.

Wycisk, C., McKelvey, B., Hulsmann, V. (2008), "Smart parts" supply networks as complex adaptive systems: analysis and implications, International Journal of Physical Distribution and Logistics Management, 38(2), pp. 108-125.

\section{Corresponding author}

Artur Świerczek can be contacted at: artur.swierczek@uekat.pl 